\title{
Elucidating the Pivotal Immunomodulatory and Anti- Inflammatory Potentials of Chloroquine and Hydroxychloroquine
}

\author{
Seidu A. Richard ${ }^{1},{ }^{1}$ Sylvanus Kampo, ${ }^{2}$ Maite Esquijarosa Hechavarria, ${ }^{2}$ Marian Sackey, ${ }^{3}$ \\ Alexis D. B. Buunaaim, ${ }^{4}$ Eugene Dogkotenge Kuugbee, ${ }^{5}$ and Thomas Winsum Anabah ${ }^{6}$ \\ ${ }^{1}$ Department of Medicine, Princefield University, P. O. Box MA128, Ho, Ghana West Africa \\ ${ }^{2}$ Department of Anesthesia and Critical Care, School of Medicine, University of Health and Allied Sciences, Ho, Ghana \\ ${ }^{3}$ Department of Pharmacy, Ho Teaching Hospital, P.O. Box MA374, Ho, Ghana West Africa \\ ${ }^{4}$ Department of Surgery, School of Medicine and Health Science, University for Development Studies, Tamale, Ghana \\ ${ }^{5}$ Department of Clinical Microbiology, School of Medicine and Health Science, University for Development Studies, Tamale, Ghana \\ ${ }^{6}$ Department of Clinical Medicine, Habana Medical Services, Tamale, Ghana
}

Correspondence should be addressed to Seidu A. Richard; gbepoo@gmail.com

Received 30 May 2020; Accepted 3 August 2020; Published 25 September 2020

Academic Editor: Roberta Antonia Diotti

Copyright (c) 2020 Seidu A. Richard et al. This is an open access article distributed under the Creative Commons Attribution License, which permits unrestricted use, distribution, and reproduction in any medium, provided the original work is properly cited.

\begin{abstract}
Chloroquine (CQ) and hydroxychloroquine (HCQ) are derivatives of 4-aminoquinoline compounds with over 60 years of safe clinical usage. CQ and HCQ are able to inhibit the production of cytokines such as interleukin- (IL-) 1, IL-2, IL-6, IL-17, and IL-22. Also, CQ and HCQ inhibit the production of interferon- (IFN-) $\alpha$ and IFN- $\gamma$ and/or tumor necrotizing factor- (TNF-) $\alpha$. Furthermore, CQ blocks the production of prostaglandins (PGs) in the intact cell by inhibiting substrate accessibility of arachidonic acid necessary for the production of PGs. Moreover, CQ affects the stability between T-helper cell (Th) 1 and Th2 cytokine secretion by augmenting IL-10 production in peripheral blood mononuclear cells (PBMCs). Additionally, CQ is capable of blocking lipopolysaccharide- (LPS-) triggered stimulation of extracellular signal-modulated extracellular signalregulated kinases $1 / 2$ in human PBMCs. HCQ at clinical levels effectively blocks CpG-triggered class-switched memory B-cells from differentiating into plasmablasts as well as producing IgG. Also, HCQ inhibits cytokine generation from all the B-cell subsets. IgM memory B-cells exhibits the utmost cytokine production. Nevertheless, CQ triggers the production of reactive oxygen species. A rare, but serious, side effect of CQ or HCQ in nondiabetic patients is hypoglycaemia. Thus, in critically ill patients, CQ and HCQ are most likely to deplete all the energy stores of the body leaving the patient very weak and sicker. We advocate that, during clinical usage of CQ and HCQ in critically ill patients, it is very essential to strengthen the CQ or HCQ with glucose infusion. CQ and HCQ are thus potential inhibitors of the COVID-19 cytokine storm.
\end{abstract}

\section{Introduction}

Chloroquine (CQ) and hydroxychloroquine (HCQ) are derivatives of 4 -aminoquinoline compounds with over 60 years of safe clinical use in the treatment of malaria and, recently, the treatment of inflammatory disorders $[1,2]$. CQ and HCQ have proven to be an effective and safe treatment option for autoimmune diseases like rheumatoid arthritis (RA) as well as systemic lupus erythematosus (SLE) $[1,3]$. Also, in recent years, CQ and HCQ have gained special attention because of the nonexistence of effective and efficient antiviral medications against new emerging viruses such as human immunodeficiency virus (HIV), dengue virus, chikungunya virus, and Ebola virus [4-6]. These compounds are readily available, cost effective, highly tolerated by the body, and elicit very critical immunomodulatory activities [4]. The structure and mechanism of action of CQ and HCQ are exactly the same except for an extra hydroxy moiety in one terminal in HCQ $[7,8]$.

After oral ingestion, CQ and HCQ are absolutely and rapidly absorbed into the blood stream [2]. The proteins in both compounds are bound in plasma and partly 
metabolized through the cytochrome P450 (CYP) enzymes in the liver [2]. CQ undergoes hepatic modifications via the $\mathrm{N}$-dealkylation pathway into two functional metabolites such as desethyl-CQ and bisdesethyl-CQ. In human liver microsomes, CYP2C8 and CYP3A4/5 are the key enzymes accountable for the CQ N-desethylation to desethyl-CQ [2, 9]. On the other hand, HCQ is metabolized into one main metabolite, N-desethyl-HCQ, by CYP enzymes CYP2D6, CYP2C8, CYP3A4, and CYP3A5 via the N-desethylation pathway. In vivo studies have demonstrated a correlation between blood N-desethyl-HCQ levels and effectiveness of HCQ $[2,10]$.

CQ and HCQ amass in tissues with elevated levels in the liver, brain, heart, muscle, and skin than the blood after prolong usage $[2,11,12]$. Therefore, it was speculated that tissue levels may be more associated with their effectiveness than blood levels $[2,13]$. Studies have demonstrated that the buildup of CQ and HCQ in lymphocytes as well as macrophages resulted in anti-inflammatory activities in diverse viral diseases depicted with the overproduction of tumor necrosis factor- $\alpha$ (TNF- $\alpha$ ) by the alveolar macrophages [14, 15]. Also, CQ precisely blocked TNF, interleukin- (IL-) 6, and prostaglandin (PG) E release without modulating the expression of IL-1 by normal macrophages [16].

CQ and HCQ are capable of modulating immune players like toll-like receptors (TLRs), T-cells, B-cells, interferons (IFNs), mitogen-activated protein kinase (MAPK), chemokines, and generation of reactive oxygen species (ROS) [1722]. This review therefore explicitly explores the key immune and inflammatory players modulated by CQ and HCQ. Most of the articles reviewed were indexed in PubMed with strict inclusion criteria being in vitro and in vivo up- or downregulation of these immune and inflammatory biomarkers in different disease conditions.

\section{Mechanism of Action and Dosage}

CQ and HCQ easily penetrate the lipid bilayer due to their small lipophilic nature after oral or intramuscular administration $[23,24]$. Inside the cell, these diprotic weak bases diffuse across a pH gradient into acidic subcellular compartments like endolysosomes where they become diprotonated at lower $\mathrm{pH}[23,25]$. The diprotonated CQ and HCQ accumulates inside endolysosomes up to 10,000-fold elevations as compared to their extracellular levels leading to curatively accessible intracellular levels in the millimolar range $[23,24,26]$. These drugs inhibited protein synthesis and processing, as well as degradation via mechanisms involving alkalization of endosomes and lysosomes [23]. Nevertheless, extra actions of the drugs seem to be independent of lysosomotropism [23, 27].

Also, these drugs are capable of interrelating with DNA resulting in the modification of its super helical structure, as well as inhibition of DNA synthesis at extreme concentrations $[23,27]$. Furthermore, studies have shown that they are capable of inhibiting inositol 1,4,5-triphosphate signaling as well as protein phosphorylation [23, 28]. Qu et al. demonstrated that the total ROS and mitochondrial (mt) ROS levels in QBC939 cells were obviously augmented while mitochon- drial membrane potentials were obviously diminished after CQ treatment [29]. CQ and CHQ are capable of neutralizing the cellular acidic compartments containing lysosomes as well as endosomes [30-32]. They have been implicated in the modification and the intracellular trafficking of newly synthesized proteins [30-32]. HCQ can regulate human inflammatory macrophage polarization through the downregulation of M1 contrary to the upregulation of M2 macrophages $[33,34]$.

CQ was capable of inhibiting the function of lysosomes, leading to a widespread blockage of autophagy [29]. It was established that oxidized proteins cannot be damaged by molecular chaperone-mediated autophagy in lysosomes, which are inhibited by CQ [29]. Thus, CQ is likely to have a robust blockade effect on the antioxidant capacity and cell-death-stimulatory properties $[29,35]$. Studies have demonstrated that CQ triggered a bitter taste receptor (TAS2R) leading to an upsurge in intracellular $\mathrm{Ca}^{2+}$ via the $\mathrm{G} \beta \gamma$ PLC $\beta$-IP3-IP3R signaling pathway in the airway smooth muscle [36-38]. It was also established that the upsurge in $\mathrm{Ca}^{2+}$ was probably mediated in the CQ-triggered glucose transporter 4 (GLUT4) trafficking to the plasma membrane [36].

The plasma concentration of CQ peaked half an hour after administration while the plasma concentration of HCQ peaked within 3-4 hours after administration [39, 40]. A study revealed that the action of CQ and HCQ in the blockade of TNF- $\alpha$, IL- $1 \beta$, and IL- 6 synthesis operated via diverse approaches and their therapeutic doses were capable of suppressing the production of TNF- $\alpha$, IL- $1 \beta$, and IL- 6 in patients [30]. The intracellular concentrations of HCQ in mononuclear cells from patients on a 3-month course of standard dose of $400 \mathrm{mg}$ daily was similar to that in mononuclear cells incubated in vitro with $100 \mu \mathrm{M}$ CQ or HCQ for 1 hour [26, 30]. CQ and HCQ have long terminal as well as elimination half-lives of 22 and 20-60 days, respectively [39, 40]. Nevertheless, the excretion HCQ in the urine persists up to 3 months from the time of the last dose [39].

CQ and HCQ are mostly in tablet formula for oral usage as CQ phosphate $500 \mathrm{mg}$ which is equivalent to $300 \mathrm{mg}$ CQ base and HCQ sulfate $200 \mathrm{mg}$ which is equivalent to $155 \mathrm{mg}$ HCQ base active drug per tablet, respectively [39]. It is advocated that, in autoimmune diseases like rheumatoid arthritis and systemic lupus erythematosus, the doses of CQ and HCQ should not exceed $500 \mathrm{mg} /$ day and $400 \mathrm{mg} /$ day, respectively [39]. Nevertheless, in acute malaria, doses as high as $2000 \mathrm{mg}$ CQ and HCQ have been used [39, 40]. We are of the view that these drugs may target the protozoan cells with less affinity for normal body cells in malaria, thus reducing the adverse effects of the drugs due to high concentrations in the protozoan cells and lesser concentration in the normal body cells.

In viral as well as autoimmune diseases, the drugs may target only the normal body cells, thereby increasing adverse effects with doses exceeding $500 \mathrm{mg} /$ day for CQ and $400 \mathrm{mg} /$ day for HCQ. Complications like retinopathy and QTc prolongation with consequential possibility of ventricular arrhythmias have been associated with CQ and HCQ [39]. CQ has higher possibilities of retinopathy than HCQ though 
short-term dosing of both medicines has no such complication $[39,41]$.

\section{Toll-Like Receptor (TLR)}

The key mechanism of action of HCQ is the blockade of nucleic acid-sensing toll-like receptors (TLRs) [17]. The inhibitory effect of nucleic acid-sensing TLRs occurs as a result of reduction in endosomal $\mathrm{pH}$ or direct binding of nucleic acid machineries to the TLRs [17-19]. In both in vitro and in vivo experimental prototypes, CQ inhibited proinflammatory cytokine secretion triggered by microbial TLR ligands via downregulating TLR-9 and TLR-4 mRNA secretion, inhibiting NF- $\kappa \mathrm{B}$ as well as activated protein-1 (AP-1) stimulation, interfering with endosome maturation, and blockade of nucleic acid binding to TLR-7, TLR-8, and TLR-9 (Table 1) [42, 43]. Studies have shown that CQ was capable of triggering endosomal acidification and fusion, thus blocking the stimulation and facilitation of the virus via endocytic TLR-3, TLR-7, TLR-8, and TLR-9 (Table 1) in HIV patients [20, 21, 44]. Also, CQ was capable of inhibiting TLR-7 downregulatory signaling pathways resulting in the blockade of transcription factors like interferon regulatory factor- (IRF-) 7, which modulates the production of IFN- $\alpha$, an effective CD8 T-cell immune stimulator [20-22].

Plasmacytoid dendritic cells (pDC), which identify pathogens via TLR-7 and TLR-9, are an essential component of the innate and adaptive immune systems [22]. TLRs are intracellular, and thus, their ligands involve cellular uptake as well as endosomal maturation to trigger NF- $\kappa \mathrm{B}$ and MAPK-mediated signals via the MyD88-dependent pathway. These TLR signals result in pDC stimulation or maturation and in the generation of proinflammatory cytokines as well as huge quantities of IFNs- $\alpha / \beta$ [22]. Martinson et al. demonstrated that CQ blocked $\mathrm{pDC}$ stimulation or maturation, upregulation of the MyD88 pathway signaling molecules like IRF-7 and IL-1 receptor-associated kinase 4 (IRAK- 4 ), IFN- $\alpha$ generation, indoleamine 2,3-dioxygenase (IDO) synthesis, and programmed death-ligand $1(\mathrm{PDL}-1)$ secretion. The precise association between these markers and CQ or HCQ in viral disease still needs further studies [22].

\section{Interferons}

IFNs have been implicated in several immune responses as triggers and modulators as well as effectors of both innate and adaptive immune systems during viral infections [45, 46]. IFNs have the capability of inhibiting viral replication and are often the most conspicuous cytokines produced during viral infections $[45,46]$. Studies have shown that the concentrations of IFN and IFN-inducible chemokines/cytokines like macrophage inflammatory protein-1 (MIP-1) and monocyte chemotactic protein-1 (MCP-1) as well as interferon-inducible protein-10 (IP-10) are associated with disease burden [47-49]. These chemokines or cytokines are measured by the different disease activity indices, the erythrocyte sedimentation rate, and anti-dsDNA antibody titers [47-49].
Cytokine and TCR-triggered IFN- $\gamma$ secretion was via separate signal transduction pathways comprising of transcription factors such as nuclear factor of activated T-cells (NFATs), signal transducer and activator of transcriptions (STATs), and nuclear factor kappa-light-chain-enhancer of activated B-cells (NF- $\kappa \mathrm{B}$ ) [45]. This resulted in the stimulation as well as the triggering of several intrinsic antiviral factors like RNA-activated protein kinase (PKR), the 2-5A system, Mx proteins, and many apoptotic pathways [45]. Studies have shown that human IFN- $\alpha$ and IFN- $\gamma$ bound to receptors and entered cells via receptor-mediated endocytosis through coated pits as well as endosomes [50,51]. Studies have indicated that IFN acted from outside the cell membrane to attain antiviral state $[50,52,53]$. Studies have further proven that the antiviral activity was triggered when IFNs bind to an insoluble matrix and the nonactivity of IFN microinjected directly into cells $[50,54,55]$.

Type I IFN offers effective innate immune machinery against a verity of viruses, but it may also stimulate pathogenic immune response, thus leading to huge loss of stimulated $\mathrm{CD} 4^{+} \mathrm{T}$-cells. Branca et al. reported that CQ induced the production of the $2^{\prime}, 5^{\prime}$-A synthetase [56]. Nevertheless, Chelbi-Alix and Thang found out that the presence of CQ during IFN treatment does not affect the triggering of the $2^{\prime}, 5^{\prime}$-A synthetase but impairs the IFN-dependent inhibition of virus growth [50]. Studies have demonstrated that CQ and HCQ inhibited the production of IFN- $\alpha$ and IFN- $\gamma$ and/or TNF- $\alpha$ (Table 1) [50]. Studies using different cell populations have demonstrated that HCQ inhibited proinflammatory cytokines, like TNF- $\alpha$, IFN- $\gamma$, IL- $1 \alpha$, and IL-6 (Table 1) [50, 57-59]. Also, HCQ inhibited the production of IFN- $\alpha$ (Table 1) in pDCs in vitro, either after stimulation by DNA-containing immune complexes or upon activation with TLR-9 agonists [60]. The explicit pathways via which CQ and HCQ trigger the release or inhibit the release of IFNs still need further studies since current evidence is paradoxical.

\section{Interleukins}

Several studies have persistently shown an inhibition of the production of cytokines such as IL-1, IL-2, IL-6, IL-17, and IL-22 (Table 1) by CQ and HCQ [30, 61]. In RA patients, IL-1 was primarily produced by monocytes and macrophages in the synovial tissue and was strongly implicated in joint destruction $[30,62]$. Studies have demonstrated that a huge quantity of IL- $1 \beta$ perhaps in the form of pro-IL- $1 \beta$ was retained in cells and the concentration of cell-associated IL$1 \beta$ was reduced by CQ (Table 1 ) $[30,63]$. This study further revealed that the blockade of IL- $1 \beta$ production stimulated by weak-base amines occurred via the inhibition of pro-IL- $1 \beta$ rather than via reduced IL- $1 \beta$ mRNA [30]. Studies have demonstrated that CQ was capable of inhibiting the release of IL$1 \beta$ via a pathway involving endolysosome-associated vesicles in lipopolysaccharide- (LPS-) stimulated monocytes [30, 64].

CQ was capable of inhibiting IL-2 generation and IL-2 mRNA stimulation as well as the alteration of IL-2 receptiveness of T-cell clones [65]. Studies have shown that IL-2 generation by $\alpha \mathrm{CD} 3 \mathrm{MoAb}$-triggered T-cells was possibly 
TABLE 1: Shows the explicit effect of CQ or HCQ on various immune/inflammatory factors.

\begin{tabular}{|c|c|c|c|}
\hline Immune/inflammatory factors & Type & Effect of CQ/HCQ & Citation \\
\hline \multirow{4}{*}{ Toll-like receptors (TLRs) } & TLR-3 & Inhibition & {$[20,21,44]$} \\
\hline & TLR-7 & Inhibition & {$[20,21,42-44]$} \\
\hline & TLR-8 & Inhibition & {$[20,21,42-44]$} \\
\hline & TLR-9 & Inhibition & {$[20,21,44]$} \\
\hline \multirow{3}{*}{ Interferons (IFNs) } & IFN- $\alpha$ & Inhibition & {$[50,57-59]$} \\
\hline & IFN- $\beta$ & Inconclusive & No data \\
\hline & IFN- $\gamma$ & Inhibition & {$[50,57-59]$} \\
\hline \multirow{6}{*}{ Interleukins } & IL-1 & Inhibition & {$[30,61-63]$} \\
\hline & IL-2 & Inhibition & {$[30,61,65,67,68]$} \\
\hline & IL-6 & Inhibition & {$[16,23,30,33,58,61,70-72]$} \\
\hline & IL-10 & Facilitator & {$[1,81]$} \\
\hline & IL-17 & Inhibition & {$[30,57,61]$} \\
\hline & IL-22 & Inhibition & {$[30,57,61]$} \\
\hline \multirow{3}{*}{ T-cells } & Th1 & Stability & {$[1,81]$} \\
\hline & Th2 & Stability & {$[1,81]$} \\
\hline & Th17 & Inconclusive & No data \\
\hline $\mathrm{CD} 4^{+}$ & Inconclusive & {$[20,82-85]$} & \\
\hline B-cells & All B-cell subsets & Inhibition & {$[17,93-95]$} \\
\hline Prostaglandins (PGs) & PGs & Inhibition & {$[98,99]$} \\
\hline Tumor necrosis factor (TNF) & TNF- $\alpha$ & Inhibition & {$[16,23,30,58,71,72,109]$} \\
\hline Extracellular signal-regulated kinases (ERK) & $1 / 2$ & Inhibition & {$[23,30,110,116]$} \\
\hline Chemokines & CXCL8 & Facilitator & {$[1]$} \\
\hline Reactive oxygen species (ROS) & - & Facilitator & {$[1,29]$} \\
\hline Glucose & - & Facilitator & {$[36,131,132,134,136,137]$} \\
\hline
\end{tabular}

modulated in an autocrine fashion [65-67]. It was affirmed that $\alpha \mathrm{CD} 3 \mathrm{MoAb}$ triggers the generation of IL-2, and IL-2 stimulated T-cell proliferation via the interrelation of IL-2 with high affinity IL-2R [65]. Nevertheless, CQ did not affect secretory levels of the IL-2R p55 chain, but it is possible that it might influence some other component of the IL-2 receptor (IL-2R) complex $[65,68]$. It was established that the interrelation between IL-2 and its receptor resulted in augmentation of IL-2 generation during CQ administration $[65,67]$. Also, blockade of $1 \mathrm{~L}-2$ generation as well as blockade of T-cell proliferation led to either rescindment of the triggering signal or blockade of IL-2 receptiveness [65]. Landewe et al. demonstrated that CQ partly blocks the internalization and completely inhibited the intracellular degradation of IL2 (Table 1) [65].
IL-6 is a pleiotropic cytokine produced by macrophages and T-cells as well as synovial fibroblasts in inflammatory joint tissues [30, 69]. IL-6 facilities synovitis by triggering antibody production due to its influence on B-cell maturation. It also triggered T-cells as well as stimulated the proliferation of synovial fibroblasts [30, 70]. CQ was capable of inhibiting IL-6 synthesis (Table 1) in LPS-stimulated mouse macrophages as well as human monocytes, though the mode of blockage was dissimilar in mouse and human cells $[16,30$, $58,71]$. Studies with human peripheral blood mononuclear cells (PBMCs) demonstrated that CQ decreased LPSinduced secretion of IL- $1 \beta$ as well as IL- 6 mRNA [23, 30, 72]. Yu et al. found that the role of HCQ in decreasing plasma IL-6 (Table 1) concentrations was highly coherent with the length of its administration, and once the medicine was 
halted, plasma IL- 6 concentrations reverted to the control concentrations [33]. They demonstrated that HCQ was capable of mimicking the influential properties of anti-IL-6 antibody by significantly decreasing the concentrations of IL- 6 in the critically ill COVID-19 patients [33].

Jang et al. observed a decreased in IL- $1 \beta$ and IL-6 (Table 1) release after treatment of PBMCs and monocytes or macrophages with CQ [30]. CQ blocked IL- $1 \beta$ and IL-6 generation via reduction of their mRNA levels, resulting in reduction in mRNA stability rather than alteration of transcriptional activity [30]. They indicated further that CQ regulated some steps involved in the synthesis as well as metabolism of IL- $1 \beta$ and IL- 6 mRNA [30]. These steps included transcription of IL- $1 \beta$ and IL- 6 genes, the processing of prime transcripts in the nucleus, the transport of processed mRNA to the cytosol, and the degradation of mRNA [30]. In their nuclear run-on analysis, transcriptional behaviors of the IL- $1 \beta$ and IL- 6 genes in LPS-stimulated monocytes or macrophages were not considerably transformed by CQ, signifying that CQ did not influence the synthesis of key transcripts of these cytokines [30].

Cruz da Silva et al. demonstrated a blockade of IL-17 and IL-22 (Table 1) supernatant levels by HCQ. They indicated that HCQ reduced helper T-cell (Th) 17 cytokine levels in the PBMCs from healthy individuals and SLE or RA patients [57]. It was established that IL-17 augmented the immune reaction by augmenting target organ inflammation as well as damage. Also, IL-17 enhances antibody production by Bcells, a significant immune player in SLE [73]. The exact mechanism via which HCQ decreased IL- 6 and IL-17 as well as IL-22 concentrations is still a matter of debate. Nevertheless, one potential explanation is that the reduction occurred via decreasing Th17 cells through a reduction in antigen presentation [57].

\section{T-Cells}

Helper T-cells (Th) are phenotypically heterogeneous in nature $[57,74]$. They are categorized based on the cytokines they generated via the innate immune system during the process of Th-cell differentiation. Th1, Th2, Th17, and regulatory T-cells (Treg) are 4 principal lineages described [57, 74]. In periphery, Treg cells are capable of triggering selfreactive lymphocytes via cell contact and expression of antiinflammatory cytokines as well as alteration of proficient antigen presenting cells, such as DCs [75-78]. Studies have shown that adoptive transfer of Treg cells decreased inflammatory diseases, like human graft versus host disease, experimental arthritis, experimental autoimmune hepatitis, experimental diabetes, and experimental autoimmune encephalomyelitis [75]. Therefore, Treg cells are suitable for the decrease of chronic inflammation perceived in most autoimmune diseases [75].

The stimulation of T-cells occurred via the triggering of T-cell receptors [65]. It was well established that stimulated T-cells triggered IL-2 mRNA resulting in the production of IL-2 protein [65]. The expressed IL-2 in turn triggered Tcell proliferation via binding to IL-2R present on activated T-cells [65]. Landewe et al. indicated that the inhibition of
T-cell proliferation by CQ means that CQ stimulated the alteration of receptor-mediated endocytosis [65]. Studies have shown that HCQ is capable of inhibiting Treg cellinduced upregulation of CD69 $[79,80]$. Nevertheless, HCQ failed to elicit inhibitory effect during evaluation of multiple proximal Treg cell-mediated signaling events such as Treg cell-induced protein tyrosine-kinase stimulation, inositol phosphate generation, and MAPK stimulation [79]. CQ affected the stability between Th1 and Th2 cytokine secretion by augmenting IL-10 production in PBMC $[1,81]$.

Several studies have demonstrated that HCQ in human immunodeficiency virus/acquired immunodeficiency syndrome (HIV/AIDS) patients stabilized CD4 T-cell counts or elevation (Table 1) when used in combination with hydroxyurea as well as didanosine [20, 82-85]. Piconi et al. demonstrated that 6-month HCQ therapy in combination with antiretroviral therapy (ART) was associated with reduced immune stimulation as well as augmented $\mathrm{CD} 4^{+} \mathrm{T}$-cell frequency [86]. Routy et al. demonstrated contrary findings compared to the Piconi et al. findings (Table 1) [20]. Routy et al. detected reduced secretion of the maturation marker CD83 on pDCs after CQ therapy, which they assumed possibly contributed to a reduction in DC-mediated inflammation [20].

A study revealed that both untreated and CQ-treated animals suffered a deep loss of $\mathrm{CD} 4^{+} \mathrm{T}$-cells during the acute phase of infection [87]. Nevertheless, the ability to regenerate peripheral $\mathrm{CD}^{+} \mathrm{T}$-cells was obviously enhanced initially and subsequently hindered by CQ therapy in the long term [87]. CQ therapy during chronic simian immune deficiency virus infection exhibited a decrease in immune stimulation as well as an enhanced recovery of $\mathrm{CD} 4^{+} \mathrm{T}$-cells, but this did not influence virus levels $[87,88]$. The precise pathways via which CQ and HCQ influence CD4 ${ }^{+}$T-cells still need further studies since current evidence is inconsistent.

\section{B-Cells}

Clusters of differentiation (CD) $19^{+}$B-cells are categorized into 3 functionally definite subsets: immunoglobulin (Ig) $\mathrm{D}^{+} \mathrm{CD} 27^{-}$naïve $\mathrm{B}$-cells, $\mathrm{IgD}^{+} \mathrm{CD} 27^{+}$IgM memory B-cells, and $\mathrm{IgD}^{-} \mathrm{CD} 27^{+}$class-switched memory B-cells [3, 17]. Class-switched memory B-cells proliferate in the peripheral blood as well as inflammatory tissues of patients with extremely vigorous RA or SLE and are linked to the worsening of these autoimmune diseases [17, 89-91]. There are 5 classes of immunoglobulins generated by antibodyproducing cells during disease process. IgG is the most effective inflammation facilitator, due to its robust antigenbinding affinity and complement-activation as well as opsonic capability $[17,92]$. Thus, IgGs produced by selfreactive B-cells are presumed to perform pathogenic autoantibody functions [17].

Studies have shown that HCQ inhibited extreme autoimmune responses as well as exerts therapeutic effects by blocking the ligation of TLRs with nucleic acids [17, 93-95]. It was established that nucleic acid-sensing TLRs are secreted by human B-cells [17, 93, 94]. These TLR ligations activated B-cells to regulate inflammatory responses via antibody and 
cytokine production, as well as antigen presentation $[17,93-$ 95]. Torigoe et al. showed that HCQ at clinical levels effectively blocked CpG-triggered class-switched memory B-cells from differentiating into plasmablasts as well as producing IgG [17]. Also, HCQ also inhibited cytokine generation from all the B-cell subsets (Table 1) [17]. IgM memory B-cells exhibited the utmost cytokine production [17].

Torigoe et al. found that TLR-9 secretion was predominantly elevated in resting $\mathrm{B}$-cells and $\mathrm{CpG}$ activation more effectively triggered B-cells to proliferate as well as differentiate into plasmablasts compared to loxoribine activation [17]. They indicated that the extremely secreted TLR-9 could sensitively identify dsDNA-containing antigens and were extremely capable of facilitating the inflammatory responses of B-cells in infection prevention as well as autoimmune diseases [17]. Studies have demonstrated that CQ decreased the survival of CpG-activated B-cells and suppressed the secretion of coactivators as well as blocked the facilitatory effect of IL-10 production (Table 1) [17, 96, 97]. Cepika et al. also affirmed that IgM memory B-cells exhibited the utmost effective cytokine-generating capability as compared to classswitched memory B-cells and naïve B-cells and HCQ competently blocked all the three B-cell subsets from producing inflammatory cytokines (Table 1) [96].

\section{Prostaglandins}

Prostaglandins (PGs) are produced in numerous types of tissue injury as well as acute and chronic inflammation $[98,99]$. The levels of exogenous PGs produced during inflammatory response often reproduced as well as augmented the cardinal signs of inflammation such as edema, erythema, and hyperalgesia $[98,99]$. Floman demonstrated that CQ blocked the production of PGs (Table 1) in the intact cell by inhibiting substrate accessibility of arachidonic acid necessary for the production of PGs [98]. Floman further indicated that CQ may decrease arachidonic acid accessibility via the blockade of phospholipase A2 activity [98]. In vitro studies using a murine hemorrhagic shock model were inconclusive on the inhibitory effect of CQ on cytokines as well as PG synthesis and the lowering of Kupffer cell function like antigen presentation and $\mathrm{I} \alpha$ secretion $[16,100]$. Contrarily, CQ and HCQ inhibited IL-1, IL-2, IL-6, IL-17, and IL-22 as well as PGs (Table 1) $[61,98,99]$.

\section{Tumor Necrotizing Factor}

Tumor necrosis factor (TNF) is a pleiotropic cytokine that partakes in crucial regulatory roles in immune and inflammatory responses via cell surface receptors $[59,101]$. Studies have identified p55 and p75 as the 2 distinctive categories of TNF receptors (TNF-R) amongst members of the TNF-R superfamily $[59,102]$. It was affirmed that the p55 TNF-R was secreted universally on the surface of almost all cell types, whereas the p75 TNF-R was secreted predominantly in hematopoietic cells as well as endothelial cells [59]. It was established that both TNF-R possess four common cysteine-rich extracellular domains via which they bind TNF with high affinity [59]. Also, the cytoplasmic regions on both receptors are different and transmit distinctive but interrelating signals. These receptors have been implicated in the stimulation of nuclear factor beta $(\mathrm{NF}-\kappa \mathrm{B})$ as well as TNF-mediated apoptosis $[59,101,103]$.

Studies revealed that p55 TNF-R intermediated in TNF signals in lethal endotoxaemia as well as nonspecific immunity to infection, whereas p75 TNF-R inhibits TNF-mediated inflammatory responses during gene knockout [59, 104, 105]. It was well established that CQ triggered downregulation of cell surface p75 TNF-R in human peripheral blood monocytes incubated with phorbol 12-myristate 13-acetate and/or BB-3103 [59, 105]. Nevertheless, in resting monocytes, the blockade effect of CQ was not observed, probably because resting monocytes exhibited low levels of TNF-R secretion [59]. It was further affirmed that cell surface p75 TNF-R considerably increased when receptor shedding was inhibited by BB-3103 but was partially blocked by CQ [59]. $\mathrm{CQ}$ also reduced the surface secretion of TNF-R in inactivated cells in a similar degree as was seen in the protein expression blocker monensin and brefeldin A [59]. Thus, CQ inhibited soluble TNF-R generation by blocking the intracellular trafficking of these molecules to the cell surface, instead of inhibiting cleavage of TNF-R on the cell surface [59].

Studies have demonstrated that TNF- $\alpha$ was crucial for the development of both the innate as well as the adaptive immune response $[23,106]$. It was affirmed that neutralization of TNF- $\alpha$ with mAbs or soluble TNF- $\alpha$ receptors resulted in enhanced clinical outcomes in certain infectious and autoimmune diseases [23, 107]. TNF- $\alpha$ was capable of modulating posttranslations at the transcriptional level. It was established that, after translation, the $26 \mathrm{kDa}$ membrane-bound pro-TNF- $\alpha$ was cleaved at the cell surface by a matrix metalloproteinase, TNF- $\alpha$ converting enzyme (ADAM-17), freeing a soluble $17 \mathrm{kDa}$ form of the cytokine $[23,108]$. It was proven that secretion of the antigenpresenting process occurred in parallel with an augmented TNF secretion by Kupffer cells as well as obvious augmentation of circulating TNF levels 2 hours after hemorrhage [16].

Monocytes and macrophages are the main source of TNF- $\alpha$ during RA pathogenesis [23, 30, 107, 109]. CQ was capable of inhibiting TNF- $\alpha$ synthesis (Table 1) in LPS-activated mouse macrophages as well as human monocytes, though the blockade route was dissimilar in the mouse and human cells [16, 30, 58, 71]. CQ blocked TNF- $\alpha$ synthesis via inhibiting the conversion of cellmediated TNF- $\alpha$ precursor to the soluble mature form, rather than blocking the stimulation of TNF- $\alpha$ mRNA or synthesis of TNF- $\alpha$ precursor (Table 1) $[30,109]$. Studies with human PBMCs revealed that CQ decreased LPStriggered secretion of TNF- $\alpha$, as well as cell-related TNF$\alpha[23,30,72]$. Jang et al. demonstrated that CQ blocked TNF- $\alpha$ secretion (Table 1 ) but did not alter the level of TNF- $\alpha$ mRNA or the synthesis of TNF- $\alpha$ precursor [30]. They indicated that blockade of TNF- $\alpha$ synthesis by CQ occurred at a posttranslational step rather than a transcriptional step [30]. Also, the blockade effect of CQ on TNF- $\alpha$ synthesis occurred at a step in the processing of pro-TNF- $\alpha$ as well as the release of mature proteins [30]. 


\section{Mitogen-Activated Protein Kinase}

The extracellular signal-regulated kinases (ERK) $1 / 2$ are meticulously necessitated for TNF transcription in some human and murine macrophage populations, whereas p38 and the c-Jun N-terminal kinase (JNK) are meticulously necessitated for posttranscriptional modulation of TNF synthesis [110-113]. It was well affirmed that ERK was stimulated via a serine-threonine kinase cascade activated by Raf phosphorylation of the ERK activating kinases like MAP/ERK kinases (MEK) 1/2 [110]. Furthermore, Raf stimulation was activated via recruitment of this protein to the membrane by the protooncogene Ras resulting in Raf phosphorylation $[110,114]$. Nevertheless, the phosphorylation of Raf at Ser259 led to inactivation of this enzyme [110, 115]. Therefore, phosphorylation at different domains led to an up- or downregulation of this signaling pathway [110]. The Raf-MEK-ERK signaling was very essential in a wide range of macrophage inflammatory activities [110].

Weber et al. demonstrated that CQ precisely inhibited the stimulation of ERK-MAP kinase proteins (Table 1) which are obligatory for prime LPS-triggered TNF secretion in human mononuclear phagocytes and murine macrophage cell line AMJ2C-8 $[23,110,116]$. CQ was also capable of blocking LPS-triggered stimulation of extracellular signalmodulated ERK1/2 in human PBMCs (Table 1) [30]. Moreover, the secretion of the TNF- $\alpha$ promoter-driven reporter gene in human monocytic THP-1 cells revealed that CQ inhibited the transcription of the TNF- $\alpha$ gene via blockade of LPS-triggered stimulation of the ERK1/2 signaling pathway $[30,110]$. Further in vitro and in vivo studies on this pathway and CQ are still warranted.

\section{Chemokines}

Chemokines are a group of molecules implicated in the trafficking of leukocytes in normal immune surveillance as well as recruitment of inflammatory cells in host defense $[1,117$, 118]. They comprise over 40 members, which are categorized into four classes based on the locations of fundamental cysteine residues such as C, CC, CXC, and CX3C [1]. CQ was capable of stimulating the mRNA and protein levels of chemokines like CCL2 and CXCL8 in human astroglial cells [1]. The stimulation of these chemokine mRNAs was detected at 3 hours, optimum at 16 hours, and persisted up to 24 hours after CQ therapy [1]. It was speculated that the upsurge in mRNA secretory levels of these proinflammatory chemokines was as a result of either transcriptional stimulation or stabilization of mRNA by CQ [1].

It was affirmed that CQ therapy resulted in stimulation of CXCL8 promoter activities (Table 1), which means that transcriptional stimulation was partially accountable for mRNA secretion of chemokines [1]. It was established that CQ triggered stimulation of the NF- $\kappa \mathrm{B}$ transcription factor, and blockade of NF- $\kappa \mathrm{B}$ stimulation inhibited CQ-triggered chemokine secretion in astroglial cells [1]. This strongly indicates that stimulation of chemokines was mediated at the transcriptional level [1].
Studies have demonstrated that leukocytes and neutrophils as well as eosinophils secreted CXCL10 during inflammation $[119,120]$. Also, monocytes, epithelia, endothelial, and stromal cells as well as keratinocytes are expressed in response to IFN- $\gamma$ during inflammation $[119,121,122]$. Th1 cells generated IFN- $\gamma$, which stimulates the CXCL10 production by diverse cell types [119]. CXCL10 in turn attracted and recruited Th1 cells, signifying the occurrence of a positive feedback loop between IFN- $\gamma$-producing Th1 cells and resident cells producing CXCL10 [119, 123]. Further studies on the effects of CQ or HCQ on the positive feedback loop between IFN- $\gamma$ producing Th1 cells and resident cells producing CXCL10 in viral diseases are warranted.

\section{Reactive Oxygen Species}

Cells produce reactive oxygen species (ROS) via metabolism and respiratory burst, as well as the respiratory chain [29]. Cells clear ROS through peroxisomes, superoxide dismutase, and the nicotinamide adenine dinucleotide phosphate(NADPH-) dependent reduction system, as well as the autophagy-lysosome pathway resulting in the regulation of reduction-oxidation (REDOX) balance in cells $[29,124]$. Several extracellular stimuli have been implicated in the stimulation of the transient upsurge in intracellular ROS levels [1, 125]. Also, inhibition of intracellular ROS led to a substantial blockade of stimulant-dependent signaling in mammalian cells $[1,125]$. In the REDOX balance adjustment process, the principal source of mitochondrial (mt) ROS was oxidative respiration. Studies have demonstrated that disruption of mitochondrial functions was capable of augmenting mtROS generation as well as triggering cell death $[29,124$, 126].

Park et al. demonstrated that ROS generated by CQ facilitated the stimulation of NF- $\kappa$ B following the secretion of chemokines in human astroglial cells (Table 1) [1]. Nevertheless, they observed that CQ did not trigger an upsurge of intracellular ROS in human monocytic U937 cells and murine microglial BV-2 as well as macrophage RAW 264.7 cells. They indicated that disparities in the immunomodulatory effect of CQ between monocytes, microglia, and astroglial cells seem to be determined at the level of ROS production following the stimulation of NF- $\kappa \mathrm{B}$ [1]. It was affirmed that CQ-triggered production of ROS was annulled by diphenyl iodonium, signifying the probability that nonphagocytic NADPH oxidase partook in the production of ROS during CQ therapy [1]. Qu et al. demonstrated that the overall ROS and mtROS levels in QBC939 cells were augmented severely after CQ administration (Table 1) while mitochondrial membrane potentials were severely reduced [29]. They concluded that CQ was capable of triggering an upsurge in ROS level (Table 1), specifically mtROS, in QBC939 cells which resulted in the loss of mitochondrial membrane potentials [29].

\section{Glucose Metabolism}

Glucose uptake is primarily reliant on GLUT4 which translocates extracellular glucose via the cell membrane into the cell 
$[36,127]$. Therefore, GLUT4 is very critical for sustenance whole-body glucose homeostasis $[36,127]$. It was well established that GLUT4 was predominantly located in intracellular GLUT4-storage vesicles (GLUT4-SVs) [127]. Studies have shown that insulin triggered fast translocation of GLUT4SVs from the trans-Golgi network and/or endosomes to the plasma membrane $[36,128]$. The fusion of GLUT4SVs with the plasma membrane led to augmented glucose uptake [128]. Further studies have demonstrated that this step was upregulated via insulin receptor or insulin receptor substrate-1(IRS-1), protein kinase B (PKB/Akt), phosphatidylinositol 3 kinase (PI3-K), and atypical protein kinase $\mathrm{C}$ (aPKC) as well as cytosolic $\mathrm{Ca}^{2+}[129,130]$.

Studies revealed that CQ facilitated cellular glucose uptake via the stimulation of GLUT4 trafficking to, and fusion with (Table 1), the cellular plasma membrane via augmentation of cellular $\mathrm{Ca}^{2+}$ uptake $[36,131,132]$. Another study demonstrated that CQ was an effective stimulator of the insulin-responsive protein like $\mathrm{PKB} / \mathrm{Akt}$ and considerably augmented glycogen synthesis via the phosphorylation of glycogen synthase kinase $3 \beta$ (GSK-3 $\beta$ ), which made it an attractive potential antidiabetic drug $[36,133]$. It was further established that the antidiabetic mechanism of CQ analogues involved reductions in insulin clearance as well as degradation rates and an upsurge in the expression of C-peptide $[134,135]$.

CQ and HCQ are well-tolerated therapeutic options for type II diabetic mellitus [134]. Glycated hemoglobin reduced considerably when HCQ was combined with insulin for the treatment of diabetes mellitus, compared with patients receiving placebo, and the insulin dose had to be lowered by $30 \%$ in the HCQ group $[134,136]$. We anticipate that, in critically ill patients, CQ and HCQ are likely to deplete all the energy stores of the body leaving the patient very weak and sicker. A study revealed that a rare, but serious, side effect of CQ or HCQ in nondiabetic patients is hypoglycaemia (Table 1) [132, 137]. Thus, during clinical usage of CQ or HCQ in critically ill patients, it is very essential to strengthen the CQ or HCQ with glucose infusion.

\section{Conclusion}

CQ and HCQ are able to inhibit the production of cytokines such as IL-1, IL-2, IL-6, IL-17, and IL-22. Also, CQ blocked TNF- $\alpha$ synthesis via inhibiting the conversion of cellmediated TNF- $\alpha$ precursor to the soluble mature form, rather than blocking the stimulation of TNF- $\alpha$ mRNA or synthesis of TNF- $\alpha$ precursor. Furthermore, CQ was also capable of inhibiting IL-2 generation and IL-2 mRNA stimulation as well as the alteration of IL-2 receptiveness of T-cell clones. Similarly, HCQ also inhibits cytokine generation from all the B-cell subsets. IgM memory B-cells exhibit the utmost cytokine production. Nevertheless, CQ is capable of producing ROS via a facilitated stimulation of NF- $\kappa \mathrm{B}$ and following secretion of chemokines in human astroglial cells. A rare, but serious, side effect of CQ or HCQ in nondiabetic patients is hypoglycaemia. We advocate that, in critically ill patients, CQ and HCQ are more likely to deplete all the energy stores of body leaving the patient very weak and sicker. Thus, during clinical usage of CQ or HCQ in critically ill patients, it is very essential to strengthen the CQ or HCQ with glucose infusion. CQ and HCQ are thus potential inhibitors of the COVID-19 cytokine storm.

\section{Abbreviations}

AP-1: $\quad$ Activated protein-1

aPKC: Atypical protein kinase C

CD: $\quad$ Cluster of differentiation

CQ: Chloroquine

CYP: $\quad$ Cytochrome P450

ERK1/2: $\quad$ Extracellular signal-regulated kinases

GLUT4: Glucose transporter 4

GLUT4SVs: GLUT4 storage vesicles

HIV: Human immunodeficiency virus

HCQ: Hydroxychloroquine

IL: Interleukin

IL-2R: IL-2 receptor

IRF: Interferon regulatory factor

IFN: Interferon

IRS-1: Insulin receptor substrate-1

JNK: $\quad$-Jun N-terminal kinase

MAPK: $\quad$ Mitogen-activated protein kinase

mt: $\quad$ Mitochondrial

NFATs: $\quad$ Nuclear factor of activated T-cells

NF- $\kappa$ B: $\quad$ Nuclear factor kappa-light-chain-enhancer of activated B-cells

NADPH: Nicotinamide adenine dinucleotide phosphate

PI3-K: $\quad$ Phosphatidylinositol 3 kinase

pDC: $\quad$ Plasmacytoid dendritic cells

PGs: $\quad$ Prostaglandins

PKR: $\quad$ Protein kinase

PBMCs: $\quad$ Peripheral blood mononuclear cells

ROS: $\quad$ Reactive oxygen species

RA: Rheumatoid arthritis

REDOX: Reduction-oxidation

Treg: Regulatory T-cells

SLE: Systemic lupus erythematosus

STATs: $\quad$ Signal transducer and activator of

Th: T-helper cell

TNF: $\quad$ Tumor necrotizing factor

TLRs: Toll-like receptors.

\section{Conflicts of Interest}

The authors declare that they have no conflicts of interest.

\section{Authors' Contributions}

All authors contributed toward the literature search, drafting, and critical revision of the paper and agree to be accountable for all aspects of the work.

\section{References}

[1] J. Park, K. Choi, E. Jeong, D. Kwon, E. N. Benveniste, and C. Choi, "Reactive oxygen species mediate chloroquine- 
induced expression of chemokines by human astroglial cells," Glia, vol. 47, no. 1, pp. 9-20, 2004.

[2] D. Plantone and T. Koudriavtseva, "Current and future use of chloroquine and hydroxychloroquine in infectious, immune, neoplastic, and neurological diseases: a mini-review," Clinical Drug Investigation, vol. 38, no. 8, pp. 653-671, 2018.

[3] C. Vasquez, M. A. Franco, and J. Angel, "Rapid proliferation and differentiation of a subset of circulating IgM memory B cells to a CpG/cytokine stimulus in vitro," PLOS ONE, vol. 10, no. 10, article e0139718, 2015.

[4] S. D’Alessandro, D. Scaccabarozzi, L. Signorini et al., "The use of antimalarial drugs against viral infection," Microorganisms, vol. 8, no. 1, p. 85, 2020.

[5] F. Touret and X. de Lamballerie, "Of chloroquine and COVID-19," Antiviral Research, vol. 177, article 104762, 2020.

[6] A. M. Hashem, B. S. Alghamdi, A. A. Algaissi et al., "Therapeutic use of chloroquine and hydroxychloroquine in COVID-19 and other viral infections: a narrative review," Travel Medicine and Infectious Disease, vol. 35, article 101735, 2020.

[7] A. K. Singh, A. Singh, A. Shaikh, R. Singh, and A. Misra, "Chloroquine and hydroxychloroquine in the treatment of COVID-19 with or without diabetes: a systematic search and a narrative review with a special reference to India and other developing countries," Diabetes \& Metabolic Syndrome: Clinical Research \& Reviews, vol. 14, no. 3, pp. 241-246, 2020.

[8] D. J. Browning, "Pharmacology of chloroquine and hydroxychloroquine," in Hydroxychloroquine and Chloroquine Retinopathy, pp. 35-63, Springer, New York, NY, 2014.

[9] K.-A. Kim, J.-Y. Park, J.-S. Lee, and S. Lim, "Cytochrome P450 2C8 and CYP3A4/5 are involved in chloroquine metabolism in human liver microsomes," Archives of Pharmacal Research, vol. 26, no. 8, pp. 631-637, 2003.

[10] T. Munster, J. P. Gibbs, D. Shen et al., "Hydroxychloroquine concentration-response relationships in patients with rheumatoid arthritis," Arthritis \& Rheumatism, vol. 46, no. 6, pp. 1460-1469, 2002.

[11] A. H. Mackenzie, "Dose refinements in long-term therapy of rheumatoid arthritis with antimalarials," The American Journal of Medicine, vol. 75, no. 1, pp. 40-45, 1983.

[12] E. W. McChesney, "Animal toxicity and pharmacokinetics of hydroxychloroquine sulfate," The American Journal of Medicine, vol. 75, no. 1, pp. 11-18, 1983.

[13] L. Durcan, W. A. Clarke, L. S. Magder, and M. Petri, "Hydroxychloroquine blood levels in systemic lupus erythematosus: clarifying dosing controversies and improving adherence," The Journal of Rheumatology, vol. 42, no. 11, pp. 20922097, 2015.

[14] A. Savarino, J. R. Boelaert, A. Cassone, G. Majori, and R. Cauda, "Effects of chloroquine on viral infections: an old drug against today's diseases," The Lancet Infectious Diseases, vol. 3, no. 11, pp. 722-727, 2003.

[15] R. Baughman, E. E. Lower, and R. M. du Bois, "Sarcoidosis," Lancet, vol. 361, no. 9363, pp. 1111-1118, 2003.

[16] W. Ertel, M. H. Morrison, A. Ayala, and I. Chaudry, "Chloroquine attenuates hemorrhagic shock-induced suppression of Kupffer cell antigen presentation and major histocompatibility complex class II antigen expression through blockade of tumor necrosis factor and prostaglandin release," Blood, vol. 78, no. 7, pp. 1781-1788, 1991.
[17] M. Torigoe, K. Sakata, A. Ishii, S. Iwata, S. Nakayamada, and Y. Tanaka, "Hydroxychloroquine efficiently suppresses inflammatory responses of human class-switched memory B cells via toll-like receptor 9 inhibition," Clinical Immunology, vol. 195, pp. 1-7, 2018.

[18] A. Kužnik, M. Benčina, U. Švajger, M. Jeras, B. Rozman, and R. Jerala, "Mechanism of endosomal TLR inhibition by antimalarial drugs and imidazoquinolines," The Journal of Immunology, vol. 186, no. 8, pp. 4794-4804, 2011.

[19] R. I. Fox, "Mechanism of action of hydroxychloroquine as an antirheumatic drug," Seminars in Arthritis and Rheumatism, vol. 23, no. 2, pp. 82-91, 1993.

[20] J. P. Routy, J. Angel, M. Patel et al., "Assessment of chloroquine as a modulator of immune activation to improve CD4 recovery in immune nonresponding HIV-infected patients receiving antiretroviral therapy," HIV Medicine, vol. 16, no. 1, pp. 48-56, 2015.

[21] M. Ries, K. Pritschet, and B. Schmidt, "Blocking type I interferon production: a new therapeutic option to reduce the HIV-1-induced immune activation," Clinical and Developmental Immunology, vol. 2012, Article ID 534929, 9 pages, 2012.

[22] J. A. Martinson, C. J. Montoya, X. Usuga, R. Ronquillo, A. L. Landay, and S. N. Desai, "Chloroquine modulates HIV-1induced plasmacytoid dendritic cell alpha interferon: implication for T-cell activation," Antimicrobial Agents and Chemotherapy, vol. 54, no. 2, pp. 871-881, 2010.

[23] S. M. Weber and S. M. Levitz, "Chloroquine interferes with lipopolysaccharide-induced TNF- $\alpha$ gene expression by a nonlysosomotropic mechanism," The Journal of Immunology, vol. 165, no. 3, pp. 1534-1540, 2000.

[24] P. M. O'Neill, P. G. Bray, S. R. Hawley, S. A. Ward, and B. K. Park, "4-Aminoquinolines-Past, present, and future; A chemical perspective," Pharmacology \& Therapeutics, vol. 77, no. 1, pp. 29-58, 1998.

[25] H. H. van Es, H. Renkema, H. Aerts, and E. Schurr, "Enhanced lysosomal acidification leads to increased chloroquine accumulation in $\mathrm{CHO}$ cells expressing the pfmdr1 gene," Molecular and Biochemical Parasitology, vol. 68, no. 2, pp. 209-219, 1994.

[26] J. French, N. Hurst, M. O'Donnell, and W. Betts, "Uptake of chloroquine and hydroxychloroquine by human blood leucocytes in vitro: relation to cellular concentrations during antirheumatic therapy," Annals of the Rheumatic Diseases, vol. 46, no. 1, pp. 42-45, 1987.

[27] H. Bröll, "Effect of chloroquine diphosphate on the superhelix structure of DNA and protein synthesis in synovial cells in chronic polyarthritis," Wiener Klinische Wochenschrift, vol. 95, no. 24, pp. 877-880, 1983.

[28] H. Kalisz, G. Pohlig, and H. Holzer, "Inhibition of protein phosphorylation by chloroquine," Archives of Microbiology, vol. 147, no. 3, pp. 235-239, 1987.

[29] X. Qu, J. Sheng, L. Shen et al., “Autophagy inhibitor chloroquine increases sensitivity to cisplatin in QBC939 cholangiocarcinoma cells by mitochondrial ROS," PLOS ONE, vol. 12, no. 3, article e0173712, 2017.

[30] C.-H. Jang, J.-H. Choi, M.-S. Byun, and D.-M. Jue, "Chloroquine inhibits production of TNF- $\alpha$, IL- $1 \beta$ and IL- 6 from lipopolysaccharide-stimulated human monocytes/macrophages by different modes," Rheumatology, vol. 45, no. 6, pp. 703-710, 2006. 
[31] F. R. Maxfield, "Weak bases and ionophores rapidly and reversibly raise the $\mathrm{pH}$ of endocytic vesicles in cultured mouse fibroblasts," The Journal of Cell Biology, vol. 95, no. 2, pp. 676-681, 1982.

[32] P. O. Seglen, "[59] Inhibitors of lysosomal function," in Methods in enzymology, vol. 96, pp. 737-764, 1983.

[33] B. Yu, C. Li, P. Chen et al., "Low dose of hydroxychloroquine reduces fatality of critically ill patients with COVID-19," Science China Life Sciences, vol. 1, 2020.

[34] H. Shiratori, C. Feinweber, S. Luckhardt et al., "An in vitro test system for compounds that modulate human inflammatory macrophage polarization," European Journal of Pharmacology, vol. 833, pp. 328-338, 2018.

[35] R. Kiffin, C. Christian, E. Knecht, and A. M. Cuervo, “Activation of chaperone-mediated autophagy during oxidative stress," Molecular Biology of the Cell, vol. 15, no. 11, pp. 4829-4840, 2004.

[36] Q. Zhou, X. Yang, M. Xiong et al., "Chloroquine increases glucose uptake via enhancing GLUT4 translocation and fusion with the plasma membrane in L6 cells," Cellular Physiology and Biochemistry, vol. 38, no. 5, pp. 2030-2040, 2016.

[37] C.-H. Zhang, L. M. Lifshitz, K. F. Uy, M. Ikebe, K. E. Fogarty, and R. ZhuGe, "Correction: The cellular and molecular basis of bitter tastant-induced bronchodilation," PLOS Biology, vol. 11, no. 3, 2013.

[38] D. A. Deshpande, W. C. Wang, E. L. McIlmoyle et al., "Bitter taste receptors on airway smooth muscle bronchodilate by localized calcium signaling and reverse obstruction," Nature Medicine, vol. 16, no. 11, pp. 1299-1304, 2010.

[39] K. A. Pastick, E. C. Okafor, F. Wang et al., "Review: Hydroxychloroquine and chloroquine for treatment of SARS-CoV-2 (COVID-19)," Open Forum Infectious Diseases, vol. 7, no. 4, 2020.

[40] J. Ducharme and R. Farinotti, "Clinical pharmacokinetics and metabolism of chloroquine," Clinical Pharmacokinetics, vol. 31, no. 4, pp. 257-274, 1996.

[41] M. F. Marmor, U. Kellner, T. Y. Lai, R. B. Melles, W. F. Mieler, and American Academy of Ophthalmology, "Recommendations on screening for chloroquine and hydroxychloroquine retinopathy (2016 revision)," Ophthalmology, vol. 123, no. 6, pp. 1386-1394, 2016.

[42] J. M. Jacobson, S. E. Bosinger, M. Kang et al., "The effect of chloroquine on immune activation and interferon signatures associated with HIV-1," AIDS Research and Human Retroviruses, vol. 32, no. 7, pp. 636-647, 2016.

[43] M. Rutz, J. Metzger, T. Gellert et al., “Toll-like receptor 9 binds single-stranded CpG-DNA in a sequence-and $\mathrm{pH}$ dependent manner," European Journal of Immunology, vol. 34, no. 9, pp. 2541-2550, 2004.

[44] H. Yasuda, A. Leelahavanichkul, S. Tsunoda et al., "Chloroquine and inhibition of toll-like receptor 9 protect from sepsis-induced acute kidney injury," American Journal of Physiology-Renal Physiology, vol. 294, no. 5, pp. F1050F1058, 2008.

[45] L. Malmgaard, "Induction and regulation of IFNs during viral infections," Journal of Interferon \& Cytokine Research, vol. 24, no. 8, pp. 439-454, 2004.

[46] G. C. Sen, "Viruses and interferons," Annual Review of Microbiology, vol. 55, no. 1, pp. 255-281, 2001.

[47] R. Willis, A. M. Seif, G. McGwin et al., "Effect of hydroxychloroquine treatment on pro-inflammatory cytokines and disease activity in SLE patients: data from LUMINA (LXXV), a multiethnic US cohort," Lupus, vol. 21, no. 8, pp. 830-835, 2012.

[48] J. W. Bauer, E. C. Baechler, M. Petri et al., "Elevated serum levels of interferon-regulated chemokines are biomarkers for active human systemic lupus erythematosus," PLOS Medicine, vol. 3, no. 12, article e491, 2006.

[49] J. W. Bauer, M. Petri, F. M. Batliwalla et al., "Interferon-regulated chemokines as biomarkers of systemic lupus erythematosus disease activity: a validation study," Arthritis \& Rheumatism, vol. 60, no. 10, pp. 3098-3107, 2009.

[50] M. Chelbi-Alix and M. N. Thang, "Chloroquine impairs the interferon-induced antiviral state without affecting the 2',5'oligoadenylate synthetase," Journal of Biological Chemistry, vol. 260, no. 13, pp. 7960-7964, 1985.

[51] K. C. Zoon, H. Arnheiter, D. Z. Nedden, D. J. Fitzgerald, and M. C. Willingham, "Human interferon alpha enters cells by receptor-mediated endocytosis," Virology, vol. 130, no. 1, pp. 195-203, 1983.

[52] H. Ankel, C. Chany, B. Galliot, M. Chevalier, and M. Robert, "Antiviral Effect of Interferon Covalently Bound to Sepharose," Proceedings of the National Academy of Sciences, vol. 70, no. 8, pp. 2360-2363, 1973.

[53] C. Chany and I. Cerutti, "Enhancement of antiviral protection against encephalomyocarditis virus by a combination of isoprinosine and interferon," Archives of Virology, vol. 55, no. 3, pp. 225-231, 1977.

[54] Y. Higashi and Y. Sokawa, "Microinjection of Interferon and $2^{\prime}, 5^{\prime}$-Oligoadenylate into Mouse L Cells and Their Effects on Virus Growth," The Journal of Biochemistry, vol. 91, no. 6, pp. 2021-2028, 1982.

[55] G. Huez, M. Silhol, and B. Lebleu, "Microinjected interferon does not promote an antiviral response in Hela cells," Biochemical and Biophysical Research Communications, vol. 110, no. 1, pp. 155-160, 1983.

[56] A. Branca, C. R. Faltynek, S. B. D'Alessandro, and C. Baglioni, "Interaction of interferon with cellular receptors. Internalization and degradation of cell-bound interferon," Journal of biological chemistry, vol. 257, no. 22, pp. 13291-13296, 1982.

[57] J. C. Silva, H. A. Mariz, L. F. Rocha Jr et al., "Hydroxychloroquine decreases Th17-related cytokines in systemic lupus erythematosus and rheumatoid arthritis patients," Clinics, vol. 68, no. 6, pp. 766-771, 2013.

[58] B. Dijkmans and C. Verweij, "Chloroquine and hydroxychloroquine equally affect tumor necrosis factor-alpha, interleukin 6 , and interferon-gamma production by peripheral blood mononuclear cells," The Journal of rheumatology, vol. 24, no. 1, pp. 55-60, 1997.

[59] J. Y. Jeong, J. W. Choi, K. I. Jeon, and D. M. Jue, "Chloroquine decreases cell-surface expression of tumour necrosis factor receptors in human histiocytic U-937 cells," Immunology, vol. 105, no. 1, pp. 83-91, 2002.

[60] K. Sacre, L. A. Criswell, and J. M. McCune, "Hydroxychloroquine is associated with impaired interferon-alpha and tumor necrosis factor-alpha production by plasmacytoid dendritic cells in systemic lupus erythematosus," Arthritis Research \& Therapy, vol. 14, no. 3, 2012.

[61] N. Costedoat-Chalumeau, B. Dunogué, N. Morel, V. Le Guern, and G. Guettrot-Imbert, "Hydroxychloroquine: a multifaceted treatment in lupus," La Presse Médicale, vol. 43, no. 6, pp. e167-e180, 2014. 
[62] W. P. Arend and J. M. Dayer, "Inhibition of the production and effects of interleukins-1 and tumor necrosis factor $\alpha$ in rheumatoid arthritis," Arthritis \& Rheumatism, vol. 38, no. 2, pp. 151-160, 1995.

[63] K. Matsushima, M. Taguchi, E. Kovacs, H. Young, and J. Oppenheim, "Intracellular localization of human monocyte associated interleukin 1 (IL 1) activity and release of biologically active IL 1 from monocytes by trypsin and plasmin," The Journal of Immunology, vol. 136, no. 8, pp. 2883-2891, 1986.

[64] C. Andrei, C. Dazzi, L. Lotti, M. R. Torrisi, G. Chimini, and A. Rubartelli, "The secretory route of the leaderless protein interleukin $1 \beta$ involves exocytosis of endolysosome-related vesicles," Molecular Biology of the Cell, vol. 10, no. 5, pp. 1463-1475, 1999.

[65] R. B. M. Landewe, A. M. M. Miltenburg, M. J. A. Verdonk et al., "Chloroquine inhibits $\mathrm{T}$ cell proliferation by interfering with IL-2 production and responsiveness," Clinical \& Experimental Immunology, vol. 102, no. 1, pp. 144-151, 1995.

[66] S. C. Meuer, R. E. Hussey, D. A. Cantrell et al., "Triggering of the T3-Ti antigen-receptor complex results in clonal T-cell proliferation through an interleukin 2-dependent autocrine pathway," Proceedings of the National Academy of Sciences, vol. 81, no. 5, pp. 1509-1513, 1984.

[67] D. Cantrell, M. Collins, and M. Crumpton, "Autocrine regulation of T-lymphocyte proliferation: differential induction of IL-2 and IL-2 receptor," Immunology, vol. 65, no. 3, pp. 343349, 1988.

[68] S. D. Voss, T. P. Leary, P. M. Sondel, and R. J. Robb, "Identification of a direct interaction between interleukin 2 and the p64 interleukin 2 receptor gamma chain," Proceedings of the National Academy of Sciences, vol. 90, no. 6, pp. 2428-2432, 1993.

[69] M. Field, C. Chu, M. Feldmann, and R. Maini, "Interleukin-6 localisation in the synovial membrane in rheumatoid arthritis," Rheumatology International, vol. 11, no. 2, pp. 45-50, 1991.

[70] S. Akira, T. Taga, and T. Kishimoto, "Interleukin-6 in biology and medicine," in Advances in immunology, vol. 54, pp. 1-78, 1993.

[71] S. Picot, F. Peyron, A. Donadille, J. Vuillez, G. Barbe, and P. Ambroise-Thomas, "Chloroquine-induced inhibition of the production of TNF, but not of IL-6, is affected by disruption of iron metabolism," Immunology, vol. 80, no. 1, pp. 127-133, 1993.

[72] I. Karres, J.-P. Kremer, I. Dietl, U. Steckholzer, M. Jochum, and W. Ertel, "Chloroquine inhibits proinflammatory cytokine release into human whole blood," American Journal of Physiology-Regulatory, Integrative and Comparative Physiology, vol. 274, no. 4, pp. R1058-R1064, 1998.

[73] J. C. Crispín and G. C. Tsokos, "Interleukin-17-producing T cells in lupus," Current Opinion in Rheumatology, vol. 22, no. 5, pp. 499-503, 2010.

[74] M. S. Maddur, P. Miossec, S. V. Kaveri, and J. Bayry, “Th17 cells: biology, pathogenesis of autoimmune and inflammatory diseases, and therapeutic strategies," The American Journal of Pathology, vol. 181, no. 1, pp. 8-18, 2012.

[75] R. Thomé, A. S. Moraes, A. L. Bombeiro et al., "Chloroquine treatment enhances regulatory $\mathrm{T}$ cells and reduces the severity of experimental autoimmune encephalomyelitis," PLOS ONE, vol. 8, no. 6, article e65913, 2013.
[76] S. Sakaguchi, "Naturally arising CD4+ regulatory T cells for immunologic self-tolerance and negative control of immune responses," Annual Review of Immunology, vol. 22, no. 1, pp. 531-562, 2004.

[77] S. Sakaguchi, T. Yamaguchi, T. Nomura, and M. Ono, "Regulatory T cells and immune tolerance," Cell, vol. 133, no. 5, pp. 775-787, 2008.

[78] T. Takahashi and S. Sakaguchi, "Naturally arising CD25+ CD4+ regulatory $\mathrm{T}$ cells in maintaining immunologic selftolerance and preventing autoimmune disease," Current Molecular Medicine, vol. 3, no. 8, pp. 693-706, 2003.

[79] F. D. Goldman, A. L. Gilman, C. Hollenback, R. M. Kato, B. A. Premack, and D. J. Rawlings, "Hydroxychloroquine inhibits calcium signals in T cells: a new mechanism to explain its immunomodulatory properties," Blood, vol. 95, no. 11, pp. 3460-3466, 2000.

[80] A. Gilman, F. Beams, M. Tefft, and A. Mazumder, "The effect of hydroxychloroquine on alloreactivity and its potential use for graft-versus-host disease," Bone Marrow Transplantation, vol. 17, no. 6, pp. 1069-1075, 1996.

[81] E. Hugosson, A. Björkman, and M. Troye-Blomberg, "Chloroquine enhances the number of IL-10 producing cells and the expression of B7-2 and ICAM-1 in in vitro-cultured PBMC," Scandinavian Journal of Immunology, vol. 55, no. 4, pp. 399-408, 2002.

[82] N. I. Paton, R. L. Goodall, D. T. Dunn et al., "Effects of hydroxychloroquine on immune activation and disease progression among HIV-infected patients not receiving antiretroviral therapy: a randomized controlled trial," Journal of the American Medical Association, vol. 308, no. 4, pp. 353-361, 2012.

[83] N. Paton and J. Aboulhab, "Hydroxychloroquine, hydroxyurea and didanosine as initial therapy for HIV-infected patients with low viral load: safety, efficacy and resistance profile after 144 weeks," HIV Medicine, vol. 6, no. 1, pp. 1320, 2005.

[84] K. Sperber, G. Chiang, H. Chen et al., "Comparison of hydroxychloroquine with zidovudine in asymptomatic patients infected with human immunodeficiency virus type 1," Clinical Therapeutics, vol. 19, no. 5, pp. 913-923, 1997.

[85] K. Sperber, M. Louie, T. Kraus et al., "Hydroxychloroquine treatment of patients with human immunodeficiency virus type 1," Clinical Therapeutics, vol. 17, no. 4, pp. 622-636, 1995.

[86] S. Piconi, S. Parisotto, G. Rizzardini et al., "Hydroxychloroquine drastically reduces immune activation in HIV-infected, antiretroviral therapy-treated immunologic nonresponders," Blood, vol. 118, no. 12, pp. 3263-3272, 2011.

[87] M. Vaccari, C. Fenizia, Z.-M. Ma et al., "Transient increase of interferon-stimulated genes and no clinical benefit by chloroquine treatment during acute simian immunodeficiency virus infection of macaques," AIDS Research and Human Retroviruses, vol. 30, no. 4, pp. 355-362, 2014.

[88] M. Ma, L. Wang, J. Yang et al., "Age-related impaired Th1 responses to PRV vaccine in vivo in aged pigs," Molecular Immunology, vol. 52, no. 3-4, pp. 217-223, 2012.

[89] S. Iwata, K. Saito, M. Tokunaga et al., "Phenotypic changes of lymphocytes in patients with systemic lupus erythematosus who are in longterm remission after B cell depletion therapy with rituximab," The Journal of Rheumatology, vol. 38, no. 4, pp. 633-641, 2011.

[90] B. Moller, D. Aeberli, S. Eggli et al., "Class-switched B cells display response to therapeutic B-cell depletion in 
rheumatoid arthritis," Arthritis Research \& Therapy, vol. 11, no. 3, 2009.

[91] M. Torigoe, S. Iwata, S. Nakayamada et al., "Metabolic reprogramming commits differentiation of human CD27+ IgD+ B cells to plasmablasts or CD27- IgD- cells," The Journal of Immunology, vol. 199, no. 2, pp. 425-434, 2017.

[92] H. W. Schroeder Jr. and L. Cavacini, "Structure and function of immunoglobulins," Journal of Allergy and Clinical Immunology, vol. 125, no. 2, pp. S41-S52, 2010.

[93] D. J. Rawlings, M. A. Schwartz, S. W. Jackson, and A. MeyerBahlburg, "Integration of B cell responses through toll-like receptors and antigen receptors," Nature Reviews Immunology, vol. 12, no. 4, pp. 282-294, 2012.

[94] E. A. Leadbetter, I. R. Rifkin, A. M. Hohlbaum, B. C. Beaudette, M. J. Shlomchik, and A. Marshak-Rothstein, "Chromatin-IgG complexes activate B cells by dual engagement of IgM and toll-like receptors," Nature, vol. 416, no. 6881, pp. 603-607, 2002.

[95] E. Bourke, D. Bosisio, J. Golay, N. Polentarutti, and A. Mantovani, "The toll-like receptor repertoire of human B lymphocytes: inducible and selective expression of TLR9 and TLR10 in normal and transformed cells," Blood, vol. 102, no. 3, pp. 956-963, 2003.

[96] A.-M. Cepika, D. Soldo Jureša, J. Morović Vergles et al., "Decrease in circulating DNA, IL-10 and BAFF levels in newly-diagnosed SLE patients after corticosteroid and chloroquine treatment," Cellular Immunology, vol. 276, no. 1-2, pp. 196-203, 2012.

[97] A.-K. Yi, D. W. Peckham, R. F. Ashman, and A. M. Krieg, "CpG DNA rescues B cells from apoptosis by activating $\mathrm{NF} \kappa \mathrm{B}$ and preventing mitochondrial membrane potential disruption via a chloroquine-sensitive pathway," International Immunology, vol. 11, no. 12, pp. 2015-2024, 1999.

[98] Y. Floman, "Prostaglandin e production by cultured inflamed rat synovium; stimulation by colchicine and inhibition by chloroquine," Prostaglandins and Medicine, vol. 1, no. 1, pp. 39-48, 1978.

[99] Y. Floman, E. Okon, and U. Zor, "The role of prostaglandins in experimental arthritis in the rat," Clinical Orthopaedics and Related Research, vol. 125, no. 125, pp. 214-220, 1977.

[100] K. Authi and J. Traynor, "Effects of antimalarial drugs on phospholipase A2 [proceedings]," British Journal of Pharmacology, vol. 66, no. 3, 1979.

[101] B. B. Aggarwal, "Tumor necrosis factors: developments during the last decade," European Cytokine Network, vol. 7, no. 2, pp. 93-124, 1996.

[102] P. W. Gray, K. Barrett, D. Chantry, M. Turner, and M. Feldmann, "Cloning of human tumor necrosis factor (TNF) receptor cDNA and expression of recombinant soluble TNF-binding protein," Proceedings of the National Academy of Sciences, vol. 87, no. 19, pp. 7380-7384, 1990.

[103] H. Hohmann, M. Brockhaus, P. Baeuerle, R. Remy, R. Kolbeck, and A. Van Loon, "Expression of the types A and B tumor necrosis factor (TNF) receptors is independently regulated, and both receptors mediate activation of the transcription factor NF-kappa B. TNF alpha is not needed for induction of a biological effect via TNF receptors," Journal of Biological Chemistry, vol. 265, no. 36, pp. 22409-22417, 1990.

[104] J. Rothe, W. Lesslauer, H. Lötscher et al., "Mice lacking the tumour necrosis factor receptor 1 are resistant to IMF- mediated toxicity but highly susceptible to infection by Listeria monocytogenes," Nature, vol. 364, no. 6440, pp. 798802, 1993.

[105] J. J. Peschon, D. S. Torrance, K. L. Stocking et al., “TNF receptor-deficient mice reveal divergent roles for p55 and p75 in several models of inflammation," The Journal of Immunology, vol. 160, no. 2, pp. 943-952, 1998.

[106] G. B. Huffnagle, G. B. Toews, M. D. Burdick et al., "Afferent phase production of TNF-alpha is required for the development of protective $\mathrm{T}$ cell immunity to Cryptococcus neoformans," The Journal of Immunology, vol. 157, no. 10, pp. 4529-4536, 1996.

[107] L. W. Moreland, S. W. Baumgartner, M. H. Schiff et al., "Treatment of rheumatoid arthritis with a recombinant human tumor necrosis factor receptor (p75)-Fc fusion protein," New England Journal of Medicine, vol. 337, no. 3, pp. 141-147, 1997.

[108] R. A. Black, C. T. Rauch, C. J. Kozlosky et al., "A metalloproteinase disintegrin that releases tumour-necrosis factor- $\alpha$ from cells," Nature, vol. 385, no. 6618, pp. 729-733, 1997.

[109] J.-Y. Jeong and D.-M. Jue, "Chloroquine inhibits processing of tumor necrosis factor in lipopolysaccharide-stimulated RAW 264.7 macrophages," The Journal of Immunology, vol. 158, no. 10, pp. 4901-4907, 1997.

[110] S. M. Weber, J.-M. Chen, and S. M. Levitz, "Inhibition of mitogen-activated protein kinase signaling by chloroquine," The Journal of Immunology, vol. 168, no. 10, pp. 5303-5309, 2002.

[111] T. van der Bruggen, S. Nijenhuis, E. van Raaij, J. Verhoef, and B. Sweder van Asbeck, "Lipopolysaccharide-induced tumor necrosis factor alpha production by human monocytes involves the raf-1/MEK1-MEK2/ERK1-ERK2 pathway," Infection and Immunity, vol. 67, no. 8, pp. 3824-3829, 1999.

[112] T. K. Means, R. P. Pavlovich, D. Roca, M. W. Vermeulen, and M. J. Fenton, "Activation of TNF- $\alpha$ transcription utilizes distinct MAP kinase pathways in different macrophage populations," Journal of Leukocyte Biology, vol. 67, no. 6, pp. 885893, 2000.

[113] J. L. Swantek, M. H. Cobb, and T. D. Geppert, "Jun Nterminal kinase/stress-activated protein kinase (JNK/SAPK) is required for lipopolysaccharide stimulation of tumor necrosis factor alpha (TNF-alpha) translation: glucocorticoids inhibit TNF-alpha translation by blocking JNK/SAPK," Molecular and Cellular Biology, vol. 17, no. 11, pp. 62746282, 1997.

[114] R. Marais, Y. Light, H. Paterson, and C. Marshall, "Ras recruits Raf- 1 to the plasma membrane for activation by tyrosine phosphorylation," The EMBO Journal, vol. 14, no. 13, pp. 3136-3145, 1995.

[115] S. Zimmermann and K. Moelling, "Phosphorylation and regulation of Raf by Akt (protein kinase B)," Science, vol. 286, no. 5445, pp. 1741-1744, 1999.

[116] A. B. Carter, M. M. Monick, and G. W. Hunninghake, "Both Erk and p38 kinases are necessary for cytokine gene transcription," American Journal of Respiratory Cell and Molecular Biology, vol. 20, no. 4, pp. 751-758, 1999.

[117] W. J. Streit, J. R. Conde, and J. K. Harrison, "Chemokines and Alzheimer's disease," Neurobiology of Aging, vol. 22, no. 6, pp. 909-913, 2001.

[118] A. Bajetto, R. Bonavia, S. Barbero, T. Florio, and G. Schettini, "Chemokines and their receptors in the central nervous 
system," Frontiers in Neuroendocrinology, vol. 22, no. 3, pp. 147-184, 2001.

[119] M. Liu, S. Guo, J. M. Hibbert et al., "CXCL10/IP-10 in infectious diseases pathogenesis and potential therapeutic implications," Cytokine \& Growth Factor Reviews, vol. 22, no. 3, pp. 121-130, 2011.

[120] K. D. Dyer, C. M. Percopo, E. R. Fischer, S. J. Gabryszewski, and H. F. Rosenberg, "Pneumoviruses infect eosinophils and elicit MyD88-dependent release of chemoattractant cytokines and interleukin-6," Blood, vol. 114, no. 13, pp. 26492656, 2009.

[121] A. D. Luster and J. V. Ravetch, "Biochemical characterization of a gamma interferon-inducible cytokine (IP-10)," The Journal of Experimental Medicine, vol. 166, no. 4, pp. 1084-1097, 1987.

[122] B. K. K. Lo, M. Yu, D. Zloty, B. Cowan, J. Shapiro, and K. J. McElwee, "CXCR3/ligands are significantly involved in the tumorigenesis of basal cell carcinomas," The American Journal of Pathology, vol. 176, no. 5, pp. 2435-2446, 2010.

[123] J. D. Campbell, V. Gangur, F. E. R. Simons, and K. T. HayGlass, "Allergic humans are hypo-responsive to CXCR3 chemokines in a Th1 immunity-promoting loop," The FASEB Journal, vol. 18, no. 2, pp. 1-19, 2003.

[124] M. P. Murphy, "How mitochondria produce reactive oxygen species," Biochemical Journal, vol. 417, no. 1, pp. 1-13, 2009.

[125] S. G. Rhee, "Redox signaling: hydrogen peroxide as intracellular messenger," Experimental \& Molecular Medicine, vol. 31, no. 2, pp. 53-59, 1999.

[126] J. Gutierrez, S. W. Ballinger, V. M. Darley-Usmar, and A. Landar, "Free radicals, mitochondria, and oxidized lipids," Circulation Research, vol. 99, no. 9, pp. 924-932, 2006.

[127] Y. Minokoshi, C. R. Kahn, and B. B. Kahn, “Tissue-specific ablation of the GLUT4 glucose transporter or the insulin receptor challenges assumptions about insulin action and glucose homeostasis," Journal of Biological Chemistry, vol. 278, no. 36, pp. 33609-33612, 2003.

[128] A. Klip, "The many ways to regulate glucose transporter 4," Applied Physiology, Nutrition, and Metabolism, vol. 34, no. 3, pp. 481-487, 2009.

[129] F. S. Thong, C. B. Dugani, and A. Klip, "Turning signals on and off: GLUT4 traffic in the insulin-signaling highway," Physiology, vol. 20, no. 4, pp. 271-284, 2005.

[130] Q. Li, X. Zhu, S. Ishikura et al., "Ca2+ signals promote GLUT4 exocytosis and reduce its endocytosis in muscle cells," American Journal of Physiology-Endocrinology and Metabolism, vol. 307, no. 2, pp. E209-E224, 2014.

[131] K. Kotani, O. D. Peroni, Y. Minokoshi, O. Boss, and B. B. Kahn, "GLUT4 glucose transporter deficiency increases hepatic lipid production and peripheral lipid utilization," Journal of Clinical Investigation, vol. 114, no. 11, pp. 16661675, 2004.

[132] M. Blignaut, Y. Espach, M. van Vuuren, K. Dhanabalan, and B. Huisamen, "Revisiting the cardiotoxic effect of chloroquine," Cardiovascular Drugs and Therapy, vol. 33, no. 1, pp. 1-11, 2019.

[133] A. E. Stenbit, T.-S. Tsao, J. Li et al., "GLUT4 heterozygous knockout mice develop muscle insulin resistance and diabetes," Nature Medicine, vol. 3, no. 10, pp. 1096-1101, 1997.

[134] M. A. A. Al-Bari, "Chloroquine analogues in drug discovery: new directions of uses, mechanisms of actions and toxic manifestations from malaria to multifarious diseases," Journal of
Antimicrobial Chemotherapy, vol. 70, no. 6, pp. 1608-1621, 2015.

[135] S. Kalia and J. P. Dutz, "New concepts in antimalarial use and mode of action in dermatology," Dermatologic Therapy, vol. 20, no. 4, pp. 160-174, 2007.

[136] A. Pareek, N. Chandurkar, N. Thomas et al., "Efficacy and safety of hydroxychloroquine in the treatment of type 2 diabetes mellitus: a double blind, randomized comparison with pioglitazone," Current Medical Research and Opinion, vol. 30, no. 7, pp. 1257-1266, 2014.

[137] M. C. M. Wasko, C. K. McClure, S. F. Kelsey, K. Huber, T. Orchard, and F. G. Toledo, "Antidiabetogenic effects of hydroxychloroquine on insulin sensitivity and beta cell function: a randomised trial," Diabetologia, vol. 58, no. 10, pp. 2336-2343, 2015. 